in vivo $35: 437-445(2021)$

doi:10.21873/invivo.12276

\title{
CD133 Expression Predicts Relapse in Patients With Locally Advanced Rectal Cancer Treated With Neoadjuvant Chemotherapy
}

\author{
HARUKA OI $^{1}$, TAKASHI OKUYAMA ${ }^{1}$, SHUNYA MIYAZAKI $^{1}$, YUKO ONO $^{2}$ and MASATOSHI OYA ${ }^{1}$ \\ Departments of ${ }^{1}$ Surgery and ${ }^{2}$ Pathology, Saitama Medical Center, Dokkyo Medical University, Saitama, Japan
}

\begin{abstract}
Aim: The aim of the present study was to explore the association between CD133 expression and postoperative relapses in patients with locally advanced rectal cancer (LARC) who received neoadjuvant chemotherapy (NAC). Patients and Methods: We retrospectively examined 52 patients with LARC (cT3-4, Nany, MO) who received oxaliplatin-based NAC before surgery. CD133 expression was evaluated using immunohistochemistry and divided into low and high expression groups. Results: High CD133 expression was observed in 22 patients (42.3\%). Patients with high CD133 expression had more frequent vessel invasion and relapse than those with low CD133 expression ( $p=0.013$ and $p=0.036$, respectively). Comparing the low with high CD133 expression groups, the 4-year relapse-free survival rates were $82.2 \% \mathrm{vs}$. $46.3 \%$ ( $p=0.009)$. Multivariate analysis indicated that CD133 expression was an independent risk factor for relapse $(H R=3.138 ; \quad 95 \% C I=1.046-9.412 ; \quad p=0.041)$. Conclusion: CD133 expression may be a predictive biomarker for postoperative relapse in patients with $L A R C$ who received $N A C$ before surgery.
\end{abstract}

In Western countries, the combination of neoadjuvant chemoradiotherapy (NACRT), total mesorectal excision (TME) surgery and adjuvant chemotherapy is the current standard of care in the management of locally advanced rectal cancer (LARC) (1). These treatments reduce local relapse rates to less than $10 \%(2-4)$. However, distant relapse rates for rectal cancer treated with NACRT have still been consistently $>25 \%(2,3)$.

This article is freely accessible online.

Correspondence to: Takashi Okuyama, Department of Surgery, Saitama Medical Center, Dokkyo Medical University, 2-1-50 Minami-Koshigaya, Koshigaya, Saitama, 343-8555, Japan. Tel: +81 489651111, Fax: +81 489651127, e-mail: okuyama615@gmail.com

Key Words: CD133 Expression, rectal cancer, relapse, neoadjuvant chemotherapy.
On the other hand, chemoradiotherapy for rectal cancer is known to be associated with several complications such as intraoperative complications, urinary and sexual dysfunction, intestinal and defecation problems, and secondary carcinogenesis $(5,6)$. Therefore, it has been suggested that in order to improve the rate of distant relapse, therapeutic strategies need to introduce earlier systemic treatments to prevent dissemination of micrometastasis (7). Neoadjuvant chemotherapy (NAC) without radiation therapy for LARC has recently been tried in order to improve distant control and avoid radiation toxicities without compromising local control $(7,8)$.

Recent studies have demonstrated that a small population of cancer cells, known as cancer stem cells (CSCs), may be the main initiation of the metastasis and recurrence (9). In addition, investigation of the CSCs characteristics, and other convincing evidence have suggested that CSCs play an important role in the resistance to chemo- and radiotherapies $(10,11)$. Although the functional role of CD133 in tumor progression and the CSC phenotype remains controversial, recent investigations have actively examined the significance of CD133 as a CSC marker $(12,13)$. Among CSC markers, CD133 is widely used to address malignant potential and prognostic biomarker in several solid cancers (14-16). Moreover, CD133-positive cells have been shown to be more resistant to chemo- and radio-therapies compared to CD133-negative tumor cells in cancer $(10,17)$.

Although it has been reported that there is a large number of predictive biomarkers associated with postoperative outcome in patients with LARC who underwent neoadjuvant therapy, the most important predictors of the postoperative outcome remain the pathological findings, which include the degree of bowel wall penetration and nodal involvement $(18,19)$. Other recent reports have also demonstrated that CD133 expression is closely associated with the postoperative outcome in LARC patients who received NACRT (20-22). To the best of our knowledge, there have yet to be any reports describing CD133 expression in patients with LARC who received NAC. Thus, the present study, evaluated CD133 expression, for the first time, in patients with LARC who received NAC. 


\section{Patients and Methods}

Patients and specimens. A total of 52 patients who were diagnosed LARC (clinical-stage T3/4 and/or Nany, and M0) and received surgical resection after NAC at Saitama Medical Center, Dokkyo Medical University in April 2010 and June 2018, were evaluated in this retrospective study. Thirty-one patients who treated with NACRT followed by surgical resection were excluded within the above period in the present study. This study was approved the Institutional Review Board at the Saitama Medical Center, Dokkyo Medical University (No.1534).

All patients were preoperatively assessed for accurate diagnosis using colonoscopy, pelvic magnetic resonance imaging (MRI), Chest and abdominopelvic computed tomography. The Kirsten rat sarcoma viral oncogene homolog (KRAS) mutation was evaluated by the preoperative biopsy tissue. The clinical lymph node metastasis was judged as lymph node-positive (N-positive) when there were perirectal or lateral pelvic lymph nodes with a diameter $\geq 7 \mathrm{~mm}$. The improvement of T (tumor) and $\mathrm{N}$ (lymph node) states after the surgical resection as compared to the pretreatment state based on the MRI before surgery, was defined as T- and Ndownstaging, respectively.

Tumors were staged according to the eighth edition of the TMN classification of malignant tumors (23). Histological effect of tumor regression was classified according to the Japanese Society for Cancer of the Colon and Rectum: Grade 0, no regression; Grade 1a, minimal effect (necrosis less than one-third of the lesion); Grade 1b, mild effect (necrosis less than two-thirds but one-third or more of the lesion); Grade 2, moderate effect (necrosis more than two-thirds of the lesion); Grade 3, absence of residual tumor cells (24). Tumors were divided into a non-responder Group (Grade0, 1a and 1b) and a responder Group (Grade 2 and 3).

Neoadjuvant therapy. The NAC regimen which was decided based on the KRAS state, was scheduled as previously described (25). If patients had proven wild-type KRAS, 2 cycles of NACSOX+Cetuximab: S-1 $\left(80 \mathrm{mg} / \mathrm{m}^{2}\right)$ from days 1 to 14 , oxaliplatin $(85$ $\left.\mathrm{mg} / \mathrm{m}^{2}\right)$ on day 1 , plus cetuximab $\left(400 \mathrm{mg} / \mathrm{m}^{2}\right.$ as the initial dose, followed $250 \mathrm{mg} / \mathrm{m}^{2} /$ week) were given. If patients had proven nonwild-type KRAS, 1-2 cycles of SOX, 2-9 cycles of NACmFOLFOX6: in 2-week cycles (5-fluorouracil bolus 400 and 2400 $\mathrm{mg} / \mathrm{m}^{2}$ continuous infusion over $46 \mathrm{~h}$, L-leucovorin $200 \mathrm{mg} / \mathrm{m}^{2}$, oxaliplatin, $85 \mathrm{mg} / \mathrm{m}^{2}$ ), or 2-3 cycles of NAC-XELOX: capecitabine $\left(1,000 \mathrm{mg} / \mathrm{m}^{2}\right)$ twice daily on days $1-14$ and oxaliplatin (130 $\mathrm{mg} / \mathrm{m}^{2}$ ) on day 1 were given. Surgical resection was planned 4-6 weeks after completion of NAC.

Surgery. Total mesorectal excision (TME) or tumor-specific mesorectal excision with/without sphincter preservation was performed by the standardized techniques. Laparoscopic surgery was performed in 44 patients $(84.6 \%)$, and a conventional open approach was performed in 8 patients $(15.4 \%)$. A sphincterpreserving operation, an abdominoperineal resection, and a Hartmann operation were performed in 28 patients $(53.8 \%)$, in 21 patients $(40.4 \%)$, and in 3 patients $(5.8 \%)$, respectively. The choice of surgical procedure and creation of a temporary diverting ostomy were depended on the surgeon's discretion. Lateral pelvic lymph-node dissection was performed in 11 patients $(21.1 \%)$, as there was suspicious node-positivity on the MRI prior to the NAC.

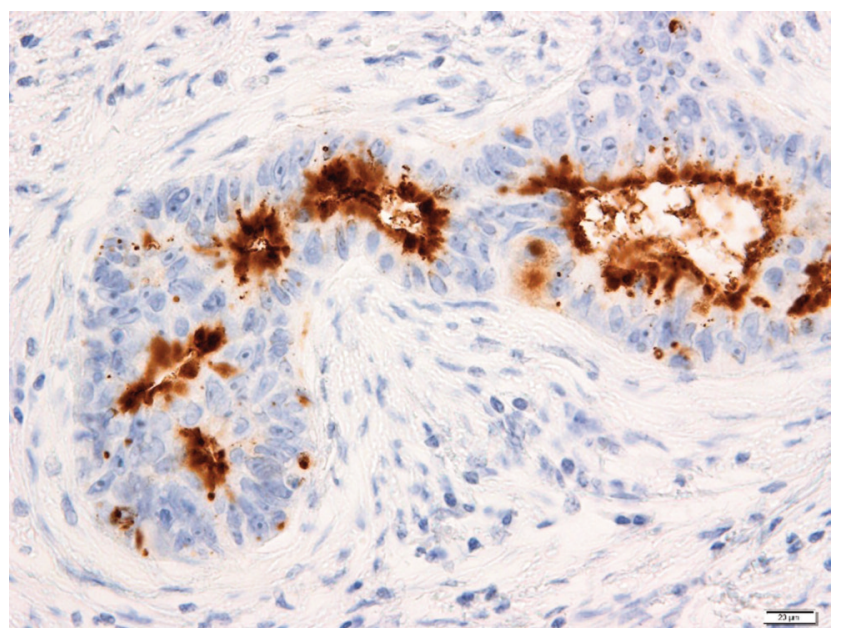

Figure 1. Immunohistochemical analysis of CD133 expression in the invasive front of primary tumors. CD133-expressing cancer cells were observed on the glandular luminal surface of rectal cancer gland and the intraglandular cellular debris. (Magnification $\times 400)$.

Postoperative follow-up and adjuvant chemotherapy. Postoperative follow-up including laboratory and physical examinations was carried out every 3 months, and CT scan of chest, abdominal and pelvis was carried out every 6 months for until 5 years after surgery. Colonoscopy were performed every 1 year. Adjuvant chemotherapy (AC) was performed to patients with ypT4 or ypN+ for 6 months using a regimen including 5FU-leucovorin, capecitabine, SOX or FOLFOX. The choice of regimen was depended on the attending physician.

Immunohistochemical staining of CD133. Tumor specimens were fixed in $10 \%$ neutral-buffered formalin for $48 \mathrm{~h}$, embedded in paraffin, cut into $4-\mu \mathrm{m}$-thick sections, and then mounted on silanecoated glass slides. Sections were deparaffinized and immersed in a $0.3 \%$ hydrogen peroxide solution in methanol for $15 \mathrm{~min}$ to inhibit endogenous peroxidase activity. After washing with phosphatebuffered saline (PBS), the sections were placed in ethylenediaminetetraacetic acid buffer at pH8.0 for CD133 staining. For antigen retrieval, slides were heated at $95^{\circ} \mathrm{C}$ for $20 \mathrm{~min}$ in a waterbath and allowed to cool at room temperature. Each slide was incubated for $1 \mathrm{~h}$ at room temperature with the primary anti-CD133 antibody (AC133; Miltenyi Biotec, Auburn, CA, USA) at a dilution of 1:100. After washing the slides three times with PBS, they were incubated with EnVision complex (Dako A/S, Glostrup, Denmark) for $20 \mathrm{~min}$ at room temperature, and after three washes with PBS, each slide was incubated for $3 \mathrm{~min}$ in $2 \% 3$, 3'-diaminobenzidine tetrahydrochloride and counterstained with hematoxylin.

Evaluation of CD133 expression. CD133 expression was evaluated in terms of the staining intensity, percentage of positive cancer cells, and staining pattern. Staining of CD133 was observed on the apical luminal surface of the rectal cancer glands, with most of the CD133positive tumors showing CD133-positive cellular debris in the glandular lumen (Figure 1) (26). CD133-positive cancer cells were counted at the apical luminal surface with/without intraluminal cell debris, with the rate of positive cancer cells in the invasive front 


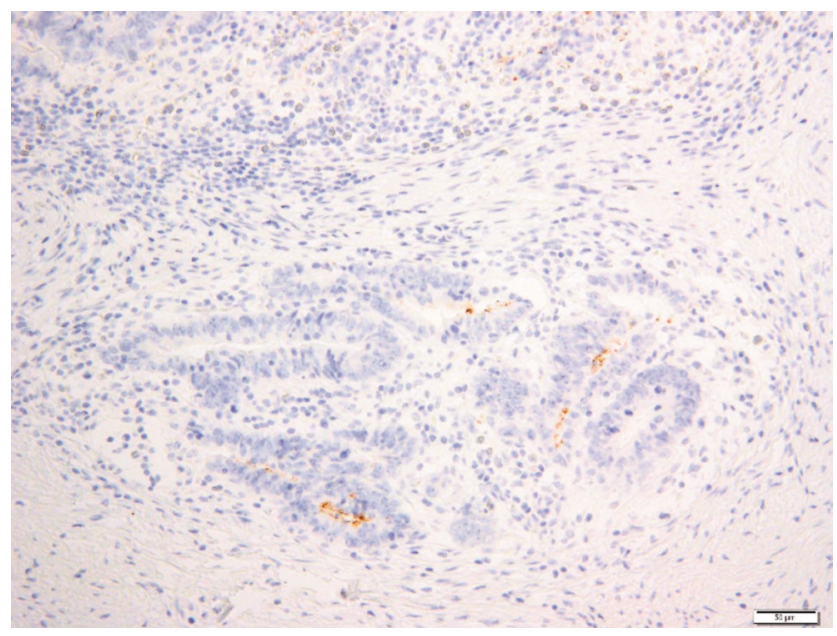

Figure 2. The cancer cell staining of CD133 in surgically resected specimens. Low CD133 expression (magnification $\times 200)$. Staining of CD133 marks a low expression group $(<50 \%)$.

determined for the primary tumor (Figure 2 and 3). Cancer cell staining of CD133 was divided into a low expression group $(<50 \%)$ and high expression group ( $\geq 50 \%$ ). Specimens were evaluated by two independent observers, with one an experienced pathologist (YO), having no knowledge of the outcomes and other clinical information, and the other a surgeon (TO). Their inter-observer agreement was calculated using $k$-statistics. The inter-observer agreement coefficient $k$ was 0.72 .

Statistical analysis. Categorical variables were compared using $\chi^{2}$ and Fisher's exact tests. Continuous variables are presented as medians and were analyzed with the Mann-Whitney $U$-test. Survival curves were plotted using the Kaplan-Meier method and compared using the log-rank test. Uni- and multivariate analyses to identify the significant factors for RFS were performed using Cox proportional hazard regression models. In the multiple analyses, a force entry method was used to identify risk factors for RFS. A $p$-value less than 0.05 was considered significant. Statistical analysis was performed using SPSS version 25 (IBM Japan Ltd., Tokyo, Japan).

\section{Results}

Baseline clinicopathological characteristics. This study evaluated 36 men (69.2\%) and 16 women (30.8), with a median age (IQR) of 67 years (range $=60-72$ years). The median follow-up period (IQR) was 53 months (range $=25$ 79). For the NAC regimens, which included SOX+cetuximab, SOX, XELOX and mFOLFOX6, there were a total of $14(26.9 \%), 21(40.4 \%), 6(11.5 \%)$ and 11 $(21.2 \%)$ patients who underwent administration of the therapy before surgical resection, respectively. The median pretreatment serum CEA levels (IQR) were 4.3 (range=2.28.4). The clinical tumor stage was cT3 in 45 patients $(86.5 \%)$

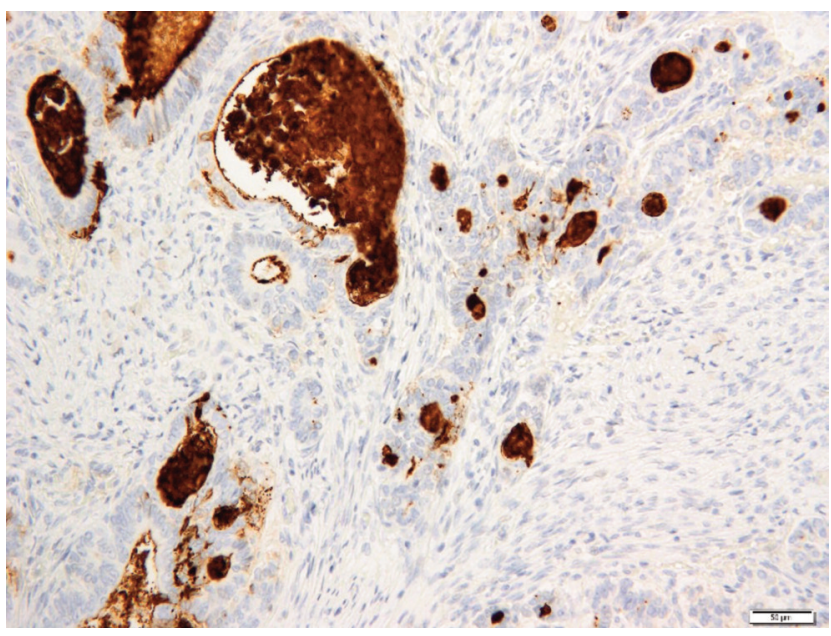

Figure 3. Cancer cell staining of CD133 in surgically resected specimens. High CD133 expression (magnification $\times 200)$. Staining of CD133 marks a high expression group ( $\geq 50 \%)$.

and cT4 (T4a and T4b) in 7 patients (13.5\%). There was clinical evidence of lymph node metastasis in 49 patients (94.2\%). Using the pathological tumor response criteria, 12 patients $(23.1 \%)$ were responders (Grades 2-3) and 40 patients $(76.9 \%)$ were non-responders (Grades $0-1 \mathrm{~b})$, and 1 patient $(2 \%)$ had a pathological complete response. Concerning the improvement of the T- and $\mathrm{N}$ - categories, Tdownstaging occurred in 15 patients $(28.8 \%)$ and $\mathrm{N}$ downstaging in 33 patients $(63.5 \%)$. The percentage of patients with $\geq 12$ examined lymph nodes was $76.9 \%$ (40/52). Surgical site infection occurred in 11 patients $(21.2 \%)$. Adjuvant chemotherapy was administered in 20 patients (38.5\%). There were $17(32.7 \%)$ out of 52 patients who developed tumor relapses, which included lung (8 patients), liver (3 patients), peritoneum (1 patient), paraaortic lymph node ( 1 patient), pelvic lymph node ( 2 patients), and local ( 2 patients). High CD133 expression was observed in 22 patients $(42.3 \%)$. Table I presents the baseline clinicopathological characteristics of the 52 patients.

Association between CD133 expression and clinicopathological characteristics. Tumors with high CD133 expression were significantly associated with more frequent vessel invasion and tumor relapse than those with low CD133 expression ( $p=0.013$ and $p=0.036$, respectively). There was a significant difference found in CD133 expression between patients who had T- and $\mathrm{N}$-downstaging and those who did not $(p=0.003$ and $p=0.012$, respectively). None of the other clinicopathological characteristics were associated with CD133 expression. Table II summarizes the correlations between the CD133 expression and the clinicopathological characteristics. 
Table I. The baseline clinicopathological characteristics of patients.

\begin{tabular}{|c|c|c|c|}
\hline Characteristics & Number $(\%)$ & Characteristics & Number $(\%)$ \\
\hline Gender & & Vessel invasion & \\
\hline Male & $36(69.2 \%)$ & Absent & $25(48.1 \%)$ \\
\hline Female & $16(30.8 \%)$ & Present & $27(51.9 \%)$ \\
\hline Age (yr, median, IQR) & $67(60-72)$ & CRM & \\
\hline Oxaliplatin based NAC & & Negative & $46(88.5 \%)$ \\
\hline SOX+Cetuximab & $14(26.9 \%)$ & Positive & $6(11.5 \%)$ \\
\hline SOX & $21(40.4 \%)$ & Pathological tumor response & \\
\hline XELOX & $6(11.5 \%)$ & Non-responder (Grade0, 1a, 1b) & $40(76.9 \%)$ \\
\hline mFOLFOX6 & $11(21.2 \%)$ & Responder (Grade2, 3) & $12(23.1 \%)$ \\
\hline Serum CEA level [median, IQR, (ng/ml)] & $4.3(2.2-8.4)$ & Responder (Grade 3) & $2(1 / 52,2 \%)$ \\
\hline Tumor size [median, IQR, $(\mathrm{mm})]$ & $45(31-50)$ & T-downstaging & \\
\hline Differentiation & & No & $37(71.1 \%)$ \\
\hline Well, Mod, pap & $49(94.2 \%)$ & Yes & $15(28.9 \%)$ \\
\hline Por, Muc, Sig & $3(5.8 \%)$ & $\mathrm{N}$-downstaging & \\
\hline Clinical Tumor depth (cT) & & No & $19(36.5 \%)$ \\
\hline $\mathrm{T} 3$ & $45(86.5 \%)$ & Yes & $33(63.5 \%)$ \\
\hline $\mathrm{T} 4 \mathrm{a}$ & $6(11.5 \%)$ & Examined lymph node & \\
\hline $\mathrm{T} 4 \mathrm{~b}$ & $1(2 \%)$ & $\geq 12$ & $40(76.9 \%)$ \\
\hline Clinical Lymph node metastasis $(\mathrm{cN})$ & & $<12$ & $12(22.1 \%)$ \\
\hline No & $3(5.8 \%)$ & Surgical approach & \\
\hline $\mathrm{N} 1$ & $33(63.5 \%)$ & Laparotomy & $8(15.4 \%)$ \\
\hline $\mathrm{N} 2$ & $5(9.5 \%)$ & Laparoscopic surgery & $44(84.6 \%)$ \\
\hline N3 & $11(21.2 \%)$ & SSI & \\
\hline Pathological tumor depth (pT) & & Absent & $41(78.8 \%)$ \\
\hline $\mathrm{CR}$ & $1(2 \%)$ & Present & $11(21.2 \%)$ \\
\hline $\mathrm{T} 1$ & $4(7.2 \%)$ & Adjuvant chemotherapy & \\
\hline $\mathrm{T} 2$ & $15(28.8 \%)$ & No & $32(61.5 \%)$ \\
\hline $\mathrm{T} 3$ & $31(60 \%)$ & Yes & $20(38.5 \%)$ \\
\hline $\mathrm{T} 4$ & $1(2 \%)$ & Postoperative relapse $(\mathrm{n}=17,32.7 \%)$ & \\
\hline Pathological Lymph node metastasis (pN) & & Lung & 8 \\
\hline No & $35(76.3 \%)$ & Liver & 3 \\
\hline $\mathrm{N} 1$ & $10(19.2 \%)$ & Peritoneum & 1 \\
\hline N2 & $6(11.5 \%)$ & Paraaortic lymph node & 1 \\
\hline N3 & $1(2 \%)$ & Pelvic lymph node & 2 \\
\hline Lymphatic invasion & & Local relapse & 2 \\
\hline Absent & $30(57.7 \%)$ & CD133 & \\
\hline \multirow[t]{2}{*}{ Present } & $22(42.3 \%)$ & Low & $30(55.7 \%)$ \\
\hline & & High & $22(42.3 \%)$ \\
\hline
\end{tabular}

NAC: Neoadjuvant chemotherapy; SOX: S-1+oxaliplatin; XELOX: capecitabine+oxaliplatine; mFOLFX: 5-fluorouracil+L-leucovorin+oxaliplatin; CRM: circumferential resection margin; SSI: surgical site infection.

CD133 expression as a risk factor for relapse. The 4-year relapse-free survival (RFS) rate for the entire study population were $67.4 \%$. Figure 4 shows the Kaplan-Meier survival curves for the RFS in the patients according the grade of CD133 expression. Patients with a low CD133 expression had a significantly better RFS rate than those with a high CD133 expression $(82.2 \%$ vs. $46.3 \%, \quad 95 \% \quad \mathrm{CI}=63.203-88.246$; $p=0.009$ ). Uni- and multi-variate analyses undertaken in order to identify factors that were related the RFS were performed using a Cox proportional hazard model (Table III). The univariate analyses showed that a more frequent lymphatic invasion $\quad(\mathrm{HR}=6.127 ; 95 \% \quad \mathrm{CI}=1.986-18.903 ; \quad p=0.002)$, circumferential resection margin $(\mathrm{CRM})$-positive $(\mathrm{HR}=13.117$;
95\% CI=4.478-38.416; $p<0.001)$, presence of lymph node metastasis $(\mathrm{HR}=4.929 ; 95 \% \mathrm{CI}=1.852-13.118 ; p=0.001)$, performance of adjuvant chemotherapy $(\mathrm{HR}=0.190 ; 95 \%$ $\mathrm{CI}=0.067-0.541 ; p=0.002), \mathrm{N}$-downstaging $(\mathrm{HR}=0.373 ; 95 \%$ $\mathrm{CI}=0.143-0.970 ; p=0.043)$ and a high CD133 expression $(\mathrm{HR}=3.475 ; 95 \% \mathrm{CI}=1.274-9.478 ; p=0.015)$ were significantly associated with a shorter RFS. Furthermore, multivariate analysis showed that CRM-positive and a high CD133 expression were factors that were significantly associated with a shorter RFS $(\mathrm{HR}=12.654 ; 95 \% \mathrm{CI}=2.668-60.015 ; p=0.001$ and $\mathrm{HR}=3.138 ; 95 \% \mathrm{CI}=1.046-9.412 ; p=0.041$, respectively). Using multivariate analyses excluding patients with CRM positive, a more frequent lymphatic invasion ( $\mathrm{HR}=2.390 ; 95 \%$ 
Table II. The relationships between CD133 expression and clinicopathological patient characteristics.

\begin{tabular}{|c|c|c|c|c|c|c|c|}
\hline & \multicolumn{2}{|c|}{ CD133 } & \multirow[b]{2}{*}{$p$-Value } & & \multicolumn{2}{|c|}{ CD133 } & \multirow[b]{2}{*}{$p$-Value } \\
\hline & Low $(\%)$ & High $(\%)$ & & & Low $(\%)$ & High $(\%)$ & \\
\hline \multicolumn{4}{|l|}{ Gender } & \multicolumn{4}{|l|}{ Vessel invasion } \\
\hline Female & $8(33.3)$ & $8(36.4)$ & 0.55 & Absent & $19(63.3)$ & $6(27.2)$ & 0.013 \\
\hline Male & $22(66.7)$ & $14(73.6)$ & & Present & $11(36.7)$ & $16(72.8)$ & \\
\hline Age & & & $0.85^{*}$ & CRM & & & \\
\hline \multicolumn{4}{|l|}{ Serum CEA level } & Negative & $28(93.3)$ & $18(81.8)$ & $0.38 * *$ \\
\hline$\leq 5$ & $20(66.7)$ & $16(72.7)$ & 0.77 & Positive & $2(6.7)$ & $4(18.2)$ & \\
\hline$>5$ & $10(33.3)$ & $6(27.3)$ & & \multicolumn{3}{|l|}{ Pathological tumor response } & \\
\hline Tumor size $(\mathrm{cm})$ & & & $0.79 *$ & Responder & $10(33.3)$ & $2(9.0)$ & $0.051 * *$ \\
\hline \multicolumn{4}{|l|}{ Differentiation } & Non-responder & $20(66.7)$ & $20(91.0)$ & \\
\hline Well, moderately, pap & $28(93.3)$ & $21(95.5)$ & $1 * *$ & \multicolumn{4}{|l|}{ T-Downstage } \\
\hline Por, Muc, Sig & $2(6.7)$ & $1(4.5)$ & & Yes & $13(43.3)$ & $2(9.0)$ & $0.003 * *$ \\
\hline \multicolumn{4}{|l|}{ pT } & No & $17(56.7)$ & $20(91.0)$ & \\
\hline T0-1 & $5(16.7)$ & $0(0)$ & $0.065^{* *}$ & \multicolumn{4}{|l|}{ N-Downstage } \\
\hline $\mathrm{T} 2-4$ & $25(83.3)$ & $22(100)$ & & Yes & $21(70.0)$ & $12(54.5)$ & 0.012 \\
\hline \multicolumn{4}{|l|}{$\mathrm{pN}$} & No & $9(30.0)$ & $10(45.5)$ & \\
\hline Absent & $23(76.7)$ & $12(54.5)$ & 0.136 & \multicolumn{4}{|l|}{ Cetuximab } \\
\hline Present & $7(23.3)$ & $10(45.5)$ & & Yes & $10(33.3)$ & $4(18.2)$ & $0.38 * *$ \\
\hline \multicolumn{4}{|l|}{ Lymphatic invasion } & No & $20(66.7)$ & $18(81.8)$ & \\
\hline Absent & $20(66.7)$ & $10(45.5)$ & 0.16 & \multicolumn{4}{|l|}{ Tumor relapse } \\
\hline \multirow[t]{2}{*}{ Present } & $10(33.3)$ & $12(54.5)$ & & Absent & $24(80.0)$ & $11(50.0)$ & 0.036 \\
\hline & & & & Present & $6(20.0)$ & $11(50.0)$ & \\
\hline
\end{tabular}

Por: Poorly; Muc: mucinous; Sig: signet; CRM: circumferential resection margin. *Mann-Whitney U analysis. **Fisher's exact test.

Table III. Uni-and multi-variate analyses to identify clinicopathological characteristics related to relapse-free survival $(n=52)$.

\begin{tabular}{|c|c|c|c|c|c|c|}
\hline \multirow[b]{2}{*}{ Predictor } & \multicolumn{3}{|c|}{ Univariate analysis } & \multicolumn{3}{|c|}{ Multivariate analysis } \\
\hline & HR & $95 \% \mathrm{CI}$ & $p$-Value & HR & $95 \% \mathrm{CI}$ & $p$-Value \\
\hline Gender (Male) & 1,234 & $0.456-3.337$ & 0.68 & & & \\
\hline Age & 0.968 & $0.968-1.012$ & 0.15 & & & \\
\hline Serum CEA level & 0.998 & $0.989-1.007$ & 0.63 & & & \\
\hline Differentiation (Por, Muc, Sig) & 1,505 & $0.199-11.387$ & 0.69 & & & \\
\hline Tumor size & 0.986 & $0.957-1.015$ & 0.34 & & & \\
\hline pT (pT2-4) & 0.616 & $0.217-1.751$ & 0.36 & & & \\
\hline Lymphatic invasion (Present) & 6,127 & $1.986-18.903$ & 0.002 & 4,742 & $0.956-23.528$ & 0.057 \\
\hline Vessel invasion (Present) & 0.52 & $0.192-1.406$ & 0.2 & & & \\
\hline CRM (Positive) & 13,117 & $4.478-38.416$ & $<0.001$ & 12,654 & $2.668-60.015$ & 0.001 \\
\hline Lymph node metastasis (Present) & 4,929 & $1.852-13.118$ & 0.001 & 2,626 & $0.339-20.360$ & 0.356 \\
\hline Histological grade (Responder) & 2,617 & $0.598-11.458$ & 0.2 & & & \\
\hline Surgical approach (Laparoscopic) & 0.658 & $0.150-2.885$ & 0.58 & & & \\
\hline Adjuvant chemotherapy (Yes) & 0.19 & $0.067-0.541$ & 0.002 & 0.503 & $0.112-2.270$ & 0.372 \\
\hline Cetuximab (Yes) & 0.539 & $0.155-1.880$ & 0.33 & & & \\
\hline T-downstaging (Yes) & 0.301 & $0.069-1.316$ & 0.11 & & & \\
\hline N-downstaging (Yes) & 0.373 & $0.143-0.970$ & 0.043 & 0.35 & $0.076-1.617$ & 0.18 \\
\hline BMI (High) & 1,021 & $0.293-3.561$ & 0.97 & & & \\
\hline CD133 (High) & 3,475 & $1.274-9.478$ & 0.015 & 3,138 & $1.046-9.412$ & 0.041 \\
\hline
\end{tabular}

Por: Poorly; Muc: mucinous; Sig: signet; CRM: circumferential resection margin; BMI: body mass index. 


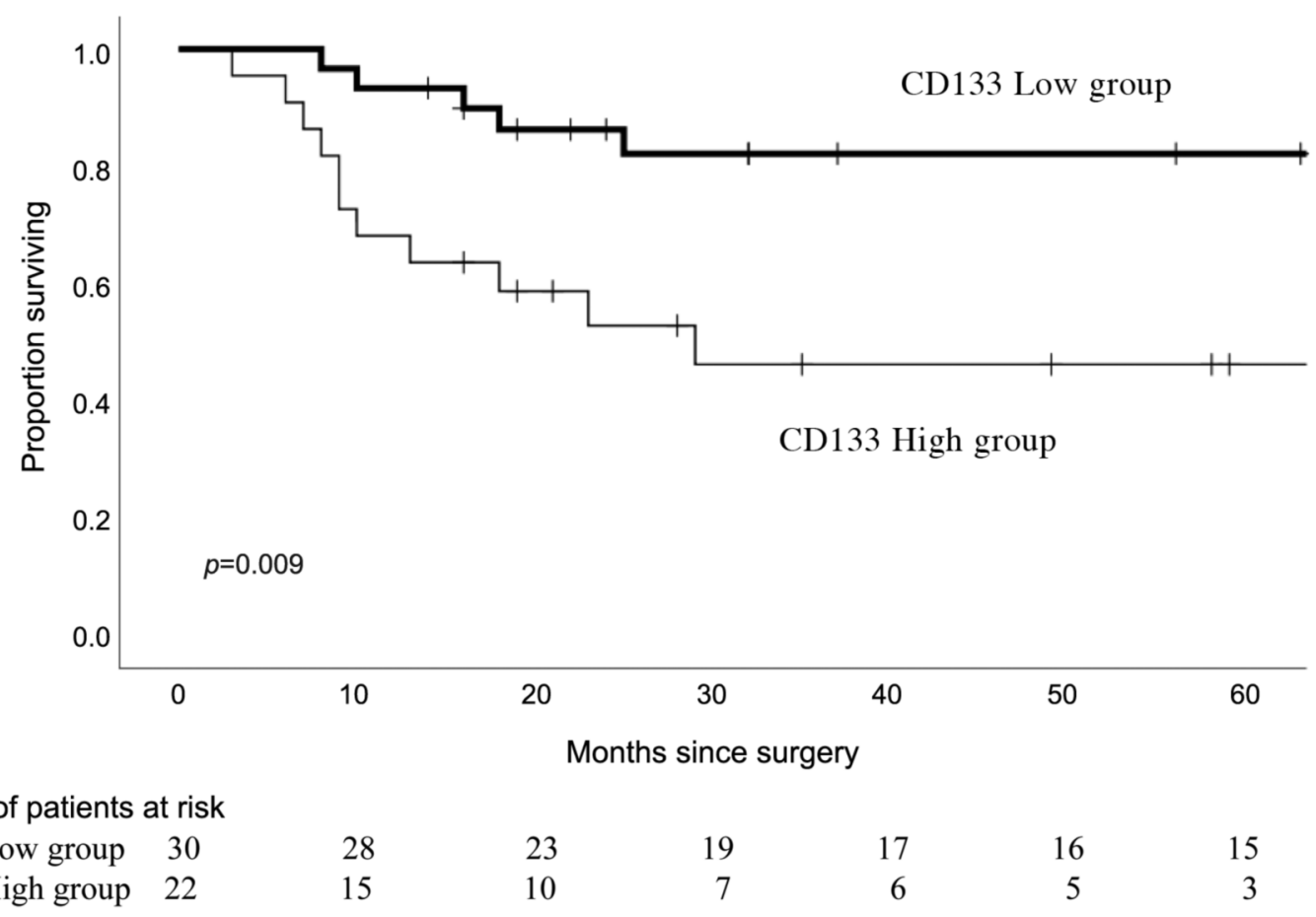

Figure 4. Kaplan-Meier survival curves for RFS in patients with a low or high CD133 expression.

$\mathrm{CI}=1.356-4.212 ; p=0.003)$ and a high $\mathrm{CD} 133$ expression $(\mathrm{HR}=3.106 ; 95 \% \mathrm{CI}=1.132-8.528 ; p=0.028)$ were significantly co-factors associated with a shorter RFS (Table IV).

\section{Discussion}

In the present study, we showed that tumors with a high CD133 expression were significantly correlated with a more frequent venous invasion and postoperative relapse. In addition, there was a significant difference in CD133 expression between patients who had $\mathrm{T}$ - and N-downstaging versus those who did not. Patients with a low CD133 expression had better RFS compared to those with a high CD133 expression. Moreover, multivariate analysis for RFS showed that CD133 expression was a significant risk factor for postoperative relapse. Based on these results, the present data suggest that CD133 expression may be predictive of postoperative relapse in patients who received NAC followed by surgical resection.

Chemo- or radio-therapy resistance is a major problem that has an influence on the survival of patients with LARC. Difference in the mechanism regarding the role of CD133 to traditional therapy resistance has yet to be fully explained at the molecular or cellular level $(10,11)$. With regard to chemotherapy, an in vitro study by Dallas et al. reported that as compared to HT29 human cancer cells with low CD133 expression, those with a high CD133 expression were able to obtain resistance to chemotherapy using 5-FU (10). It has been proposed that the mechanism of this chemoresistance was related to antiapoptotic proteins, including IL-4, and that HCC cancer cells with high CD133 expression are enriched in anti-apoptotic proteins $(13,27)$. Cancer cells with high CD133 expression are regulated by activation or suppression of signaling pathways, including Notch, TGF- $\beta$, P13k/AKT, Wnt/ $\beta$-catenin, and Hedgehog (28). CD133 can promote angiogenesis by activating Wnt signal pathway and increasing the expression of VEGF-A and interleukin-8. In addition, CD133 can accelerate the cell growth, proliferation and survival by activating the $\mathrm{P} 13 \mathrm{k} / \mathrm{AKT}$ signaling pathway and increasing the level of phosphorylated-Akt (28). However, there have yet to be any studies that have investigated CD133 expression in patients with LARC after NAC.

Cancer cells in rectal cancer specimens after NACRT were reported to be located close to the invasive front of the tumor (29). Similarly, RCCs in the present study were mostly observed at the invasive front of the tumor. Karamitopoulou et $a l$. reported that there are differences in the protein expression profiles between the invasive front and the other regions of the tumor (30). Genetic instability that results in accumulation of gene and epigenetic alternations is responsible for causing the intratumor heterogeneity (31). Marusyk et al. suggested that the CSCs, which may regulate the interaction between cancer 
Table IV. Uni-and multi-variate analyses to identify clinicopathological characteristics related to relapse-free survival excluding patients with CRM positive $(n=46)$.

\begin{tabular}{|c|c|c|c|c|c|c|}
\hline \multirow[b]{2}{*}{ Predictor } & \multicolumn{3}{|c|}{ Univariate analysis } & \multicolumn{3}{|c|}{ Multivariate analysis } \\
\hline & HR & $95 \%$ CI & $p$-Value & HR & $95 \%$ CI & $p$-Value \\
\hline Gender (Male) & 1,349 & $0.395-4.612$ & 0.63 & & & \\
\hline Age & 0.672 & $0.196-2.300$ & 0.53 & & & \\
\hline Serum CEA level & 2,414 & $0.736-7.918$ & 0.15 & & & \\
\hline Differentiation (por, muc) & 0.047 & $0.000-33307.159$ & 0.66 & & & \\
\hline Tumor size & 0.462 & $0.135-1.584$ & 0.22 & & & \\
\hline pT (pT2-4) & 24,405 & $0.008-72,674.234$ & 0.43 & & & \\
\hline Lymphatic invasion (Present) & 5,211 & $1.374-19.756$ & 0.015 & 2.39 & $1.356-4.212$ & 0.003 \\
\hline Vessel invasion (Present) & 1,261 & $0.384-4.140$ & 0.7 & & & \\
\hline Lymph node metastasis (Present) & 3,185 & $0.966-10.500$ & 0.057 & & & \\
\hline Lymph node harvest & 0.368 & $0.111-1.215$ & 0.1 & & & \\
\hline Histological grade (Responder) & 0.519 & $0.358-7.681$ & 0.52 & & & \\
\hline Surgical approach (Laparoscopic) & 0.467 & $0.060-3.658$ & 0.47 & & & \\
\hline Adjuvant chemotherapy (Yes) & 3,084 & $0.938-10.141$ & 0.064 & & & \\
\hline Cetuximab (Yes) & 4,195 & $0.536-32.837$ & 0.17 & & & \\
\hline T-downstaging (Yes) & 0.469 & $0.101-2.174$ & 0.33 & & & \\
\hline N-downstaging (Yes) & 0.487 & $0.148-1.606$ & 0.24 & & & \\
\hline BMI (High) & 1,732 & $0.458-6.547$ & 0.42 & & & \\
\hline CD133 (High) & 3.524 & $1.020-12.180$ & 0.046 & 3.106 & $1.132-8.528$ & 0.028 \\
\hline
\end{tabular}

CRM: Circumferential resection margin; Por: poorly; Muc: mucinous; Sig: signet; BMI: body mass index.

cells and the surrounding microenvironment, might also contribute to intratumor heterogeneity (32). On the other hand, several recent studies have demonstrated that CSCs promote tumor invasion and metastasis by inducing EMT processes (33, 34). Thus, the evaluation of CSCs at the invasive front of the tumor may predict the postoperative relapse in patients with LARC who received neoadjuvant therapy.

The selection of patients who need adjuvant chemotherapy after neoadjuvant therapy and TME is controversial $(35,36)$. The National Comprehensive Cancer Network (NCCN) guidelines recommended the routine use of AC in LARC patients who were treated with NACRT followed by surgery, whereas the European Society for Medical Oncology (ESMO) guidelines recommend $\mathrm{AC}$ for all stage III patients and for stage II patients with high risk factors including lymphatic and vascular invasion, pT4 lesion, and perforation $(18,19)$. In the present study, the administration of AC was determined in accordance with the criteria presented in the ESMO guidelines. In our present study, 5 out of 32 patients $(16.5 \%)$ who did not receive $\mathrm{AC}$, did develop tumor relapses during the observation period, with 3 out of these 5 patients found to have high CD133 expression. Based on these results, the examination of CD133 may be helpful when selecting patients who have a high risk for postoperative relapse.

Recently, several reports have shown that NAC could potentially have an effect on the possibility of micrometastases and reduction of distant metastases in
LARC $(7,8)$. Since it has been shown that advanced rectal cancers (cT3-4 and N-any) are associated with an increased risk of distant metastasis, which is the essential prognostic determinant in these patients, NAC could be a potential option for preventing postoperative relapses in these patients (7). In order to confirm a rectal cancer treatment strategy that incorporates a selective radiation therapy, the PROSPECT trial (ClinicalTrials.gov identifier: NCT01515787) is currently assessing this therapeutic approach in North America (37). On another recent study, the FOWARC trial in China showed that no significant difference in the 3-year disease-free survival between neoadjuvant mFOLFOX6 with or without radiation and fluorouracil plus radiation for LARC (38). Although the long-term outcomes of these studies need to be evaluated with regard to introduction of NAC without radiation therapy as a standard treatment option, we speculate that this strategy could be an effective therapy for selective patients with LARC.

There were several limitations to the present study. First, due to its retrospective design, the present study had an inherent selection bias. Second, the number of patients was not large enough to attain a sufficient power in order to reach any definitive conclusions. Therefore, a further study that includes a sufficient number of patients will need to be undertaken in order to explored the use of the CD133 expression as a useful maker for postoperative relapse. 


\section{Conclusion}

In conclusion, the present data suggest that CD133 expression in patients with LARC who have received oxaliplatin-based NAC may be useful predictive marker for postoperative relapse. Patients with a high CD133 expression therefore would be candidate for $\mathrm{AC}$, as well as requiring careful follow-up plans.

\section{Conflicts of Interest}

The Authors have no conflicts of interest to declare.

\section{Authors' Contributions}

HO, TO and MO designed the study. HO, TO, SM and MO reviewed the clinical records. YO, TO and $\mathrm{HO}$ reviewed the pathological records. All authors participated in the study design, data interpretation, and critical discussion. $\mathrm{HO}, \mathrm{TO}$, and MO wrote the manuscript. All Authors read and approved the final manuscript.

\section{Acknowledgements}

The Authors thank Mr. Takuya Okamura for excellent technical assistance.

\section{References}

1 Oronsky B, Reid T, Larson C and Knox SJ: Locally advanced rectal cancer: the past, present, and future. Semin Oncol 47(1): 85-92, 2020. PMID32147127. DOI: 10.1053/j.seminoncol. 2020.02.001

2 Sauer R, Liersch T, Merkel S, Fietkau R, Hohenberger W, Hess C, Becker H, Raab HR, Villanueva MT, Witzigmann H, Wittekind C, Beissbarth T and Rodel C: Preoperative versus postoperative chemoradiotherapy for locally advanced rectal cancer: results of the German CAO/ARO/AIO-94 randomized phase III trial after a median follow-up of 11 years. J Clin Oncol 30(16): 1926-1933, 2012. PMID: 22529255. DOI: 10.1200/ JCO.2011.40.1836

3 Ngan SY, Burmeister B, Fisher RJ, Solomon M, Goldstein D, Joseph D, Ackland SP, Schache D, McClure B, McLachlan SA, McKendrick J, Leong T, Hartopeanu C, Zalcberg J and Mackay $\mathrm{J}$ : Randomized trial of short-course radiotherapy versus longcourse chemoradiation comparing rates of local recurrence in patients with T3 rectal cancer: Trans-Tasman Radiation Oncology Group trial 01.04. J Clin Oncol 30(31): 3827-3833, 2012. PMID 23008301. DOI: 10.1200/JCO.2012.42.9597

4 Van Gijin W, Marijnen CA, Nagtegaal ID, Kranenbarg MK, Putter H, Wiggers T, Rutten HJT, Pahlman L, Glimelius B, van de Velde CJH and Dutch Colorectal Cancer Group: Preoperative radiotherapy combined with total mesorectal excision for resectable rectal cancer: 12-year follow-up of the multicenter, randomized controlled TME trial. Lancet Oncol 12(6): 575-582, 2011. PMID: 21596621. DOI: 10.1016/S1470-2045(11)70097-3

5 Ansari N, Solomon MJ, Fisher RJ, Mackay J, Burumeister B, Ackland S, Heriot A, Joseph D, McLachlan SA, McClure B and Ngan SY: Acute adverse events and postoperative complications in a randomized trial of preoperative short-course radiotherapy versus long-course chemoradiotherapy for $\mathrm{T} 3$ adenocarcinoma of rectum: Trans-Tasman Radiation Oncology Group Trial (TROG 01.04). Ann Surg 265(5): 882-888, 2017. PMID: 27631775. DOI: $10.1097 /$ SLA.0000000000001987

6 Loos M, Quentmeier P, Schuster T, Nitsche U, Gertler R, Keerl A, Kocher T, Friess H and Rosenberg R: Effect of preoperative radio (chemo) therapy on long-term functional outcome in rectal cancer patients: a systematic review and meta-analysis. Ann Surg Oncol 20(6): 1816-1828, 2013. PMID: 23269466. DOI: 10.1245/ s10434-012-2827-z

7 Schrag D, Weiser MR, Goodman KA, Gonen M, Hollywood E, Cercek A, Reidy-Lagunes D, Gollub MJ, Shia J, Guillem JG, Temple LKF, Paty PB and Saltz LB: Neoadjuvant chemotherapy without routine use of radiation therapy for patients with locally advanced rectal cancer: a pilot trial. J Clin Oncol 32(6): 513518, 2014. PMID: 24419115. DOI: 10.1200/JCO.2013.51.7904

8 Uehara K, Hiramatsu K, Maeda A, Sakamoto E, Inoue M, Kobayashi S, Tojima Y, Yoshioka Y, Nakayama G, Yatsuya H, Ohmiya N, Goto H and Nagino M: Neoadjuvant oxaliplatin and capecitabine and bevacizumab without radiotherapy for poor-risk rectal cancer: N-SOG 03 Phase II trial. Jpn J Clin Oncol 43(10): 964-971, 2013. PMID: 23935207. DOI: 10.1093/jjco/hyt115

9 Nassar D and Blanpain C: Basic concepts and therapeutic implications. Annu Rev Pathol 11: 47-76, 2016. PIMD: 27193450. DOI: 10.1146/annurev-pathol-012615-044438

10 Kozovska Z, Gabrisova V and Kucerova L: Colon cancer: cancer stem cell markers, drug resistance and treatment. Biomed Pharmacother 68(8): 911-916, 2014. PMID: 25458789. DOI: 10.1016/j.biopha.2014.10.019

11 Rycaj K and Tang DG: Cancer stem cells and radioresistance. Int J Radiat Biol 90(8): 615-621, 2014. PIMD: 24527669. DOI: 10.3109/09553002.2014.892227

12 Ricci-Vitiani L, Lombardi DG, Pilozzi E, Biffoni M, Todaro M, Peschle C and De Maria R: Identification and expansion of human colon cancer-initiating cells. Nature 445(7123): 111-115, 2007. PMID: 17122771 . DOI: $10.1038 /$ nature05384

13 Todaro M, Alea MP, Di Stefano AB, Cammareri P, Vermeulen L, Iovino F, Tripodo C, Russo A, Gulotta G, Medema JP and Stassi G: Colon cancer stem cells dictate tumor growth and resist cell death by production of interleukin-4. Cell Stem Cell 1(4): 389-402, 2007. PMID: 18371377. DOI: 10.1016/j.stem.2007.08.001

14 Ren F, Sheng WQ and Du X: CD133: A cancer stem cells marker, is used in colorectal cancers. World J Gastroenterol 19(17): 2603-2611, 2013. PMID: 23674867. DOI: 10.3748/wjg. v19.i17.2603

15 Jia ZF, Wu YH, Cao DH, Cao XY, Jiang J and Zhon BS: Polymorphisms of cancer stem cell marker gene CD133 are associated with susceptibility and prognosis of gastric cancer. Future Oncol 13(11): 979-989, 2017. PMID: 28326835. DOI: 10.2217/fon-2017-0019

16 Joseph C, Arshad M, Kurozomi S, Althobiti M, Miligy IM, AIIzzi S, Toss MS, Goh FQ, Johnston SJ, Martin SG, Ellis IO, Mongan NP, Green AR and Rakha EA: Overexpression of the cancer stem cell marker CD133 confers a poor prognosis in invasive breast cancer. Breast Cancer Res Treat 174(2): 387-399, 2019. PMID: 30554343. DOI: 10.1007/s10549-018-05085-9

17 Ong CW, Kim LG, Kong HH, Low LY, Iacopetta B, Soong R and Salto-Tellez M: CD133 expression predicts for non-response to chemotherapy in colorectal cancer. Mod Pathol 23(3): 450457, 2010. PMID: 20081809. DOI: 10.1038/modpathol.2009.181 
18 Rectal cancer, NCCN clinical practice guidelines in oncology, Version I; 2020. Available at: http//www.nccn.org/professionals/ physician.gls/pdf/rectal.pdf [Last accessed 8 February 2020]

19 Glynne-Jones R, Wyrwicz L, Tiret E, Brown G, Rodel C, Cervantes A and Arnold D: ESMO Guidelines Committee: Rectal cancer: ESMO clinical practice guidelines for diagnosis, treatment and follow-up. Ann Oncol 28(suppl 4): iv22-iv40, 2017. PMID: 32369883. DOI: 10.1093/annonc/mdx224

20 Kojima M, Ishii G, Atsumi N, Nishizawa Y, Saito N and Ochiai A: CD133 expression in rectal cancer after preoperative chemoradiotherapy. Cancer Sci 101(4): 906-912, 2010. PMID: 20219069. DOI: 10.1111/j.1349-7006.2009.01478.x

21 Shinto E, Hashiguchi Y, Ueno H, Kobayashi H, Ishiguro M, Mochizuki H, Yamamoto J and Hase K: Pretreatment of CD133 and cyclooxygenase- 2 expression as the predictive makers of the pathological effect of chemoradiotherapy in rectal cancer. Dis Colon Rectum 54(9): 1098-1106, 2011. PMID: 21825889. DOI: 10.1097/DCR.0b013e3182218155

22 Sprenger T, Conradi LC, Beissbarth T, Ermert H, Homayounfar K, Middle P, Ruschoff J, Wolff HA, Schuler P, Ghadimi BM, Rodel C, Becker H, Rodel F and Liersch T: Enrichment of CD133-expressing cells in rectal cancers treated with preoperative radiochemotherapy is an independent marker for metastasis and survival. Cancer 119(1): 26-35, 2013. PMID: 22736392. DOI: $10.1002 /$ cncr.27703

23 Brierley JD, Gospodarowicz MK and Whitekind C (eds.): American Joint Committee on Cancer (AJCC) Cancer Staging Manual. $8^{\text {th }}$ ed. New York: Springer, 2017.

24 Japanese Society for Cancer of the Colon and Rectum: Japanese Classification of Colorectal Carcinomas. Second English Edition. Tokyo, Kanehara, 2009.

25 Okuyama T, Sameshima S, Takeshita E, Yoshioka R, Yamagata Y, Ono Y, Tagaya N, Noie T and Oya M: Therapeutic effects of oxaliplatin-based neoadjuvant chemotherapy and chemoradiotherapy in patients with locally advanced rectal cancer: a single-center, retrospective cohort study. World J Surg Oncol 16(1): 105, 2018. PMID: 29871650. DOI: 10.1186/ s12957-018-1403-9

26 Horst D, Kiegl L, Engel J, Kirchner T and Junq A: CD133 expression is an independent prognostic marker for low survival in colorectal cancer. Br J Cancer 99(8): 1285-1289, 2008. PMID: 18781171. DOI: $10.1038 /$ sj.bjc. 6604664

27 Ma S, Lee TK, Zhenq BJ, Chan KW and Guan XY: CD133+ HCC cancer stem cells confer chemoresistance by preferential expression of the Akt/PKB survival pathway. Oncogene 27(12): 1749-1758, 2008. PMID: 17891174. DOI: 10.1038/sj.onc. 1210811

28 Barzeger Behrooz A, Syahir A and Ahmad S: CD133: beyond a cancer stem cell biomarker. J Drug Target 27(3): 257-269, 2019. PMID: 29911902. DOI: 10.1080/1061186X.2018.1479756

29 Duldulao MP, Lee W, Streja L, Chu P, Li W, Chen Z, Kim J and Garcia-Aguilar J: Distribution of residual cancer cells in the bowel wall after neoadjuvant chemoradiation in patients with rectal cancer. Dis Colon Rectum 56(2): 142-149, 2013. PMID: 23303141. DOI: 10.1097/DCR.0b013e31827541e2

30 Karamitopoulou E, Zlobec I, Panayiotides I, Patsouris ES, Peros G, Rallis G, Lapas C, Karakitsos P, Terracciano LM and Lugli A: Systematic analysis of proteins from different signaling pathways in the tumor center and the invasive front. Hum Pathol 42(12): 1888-1896, 2011. PMID: 21664646. DOI: 10.1016/ j.humpath.2010.06.020

31 Caiado F, Silva-Santos B and Norell H: Intra-tumor heterogeneity - going beyond genetics. FEBS J 283(12): 22452258, 2016. PMID: 26945550. DOI: 10.1111/febs. 13705

32 Marusyk A, Almendro $\mathrm{V}$ and Polyak K: Intra-tumour heterogeneity: a looking glass for cancer? Nat Rev Cancer 12(5): 323-334, 2012. PMID: 22513401. DOI: $10.1038 / \mathrm{nrc} 3261$

33 Latorre E, Carelli S, Raimondi I, D’Agostino V, Castiglioni I, Zucal C, Moro G, Luciani A, Ghilardi G, Monti E, Ingo A, Di Giulio AM, Gorio A and Provenzani A: The ribonucleic complex HuR-MALAT1 represses CD133 expression and suppresses epithelial-mesenchymal transition in breast cancer. Cancer Res 76(9): 2626-2636, 2016. PMID: 27197265. DOI: 10.1158/00085472.CAN-15-2018

34 Moon Y, Kim D, Sohn H and Lim W: Effect of CD133 overexpression on the epithelial-to-mesenchymal transition in oral cancer cell lines. Clin Exp Metastasis 33(5): 487-496, 2016. PMID: 27137188. DOI: 10.1007/s10585-016-9793-y

35 Bosset JF, Calasis G, Mineur L, Maingon P, Stojanovic-Rundic S, Bensadoun RJ, Bardet E, Beny A, Ollier JC, Bolla M, Marchal D, Van Laethem JL, Klein V, Giralt J, Clavere P, Glanzmann C, Cellier P and Collette L: EORTC Radiation Oncology Group: Fluorouracil-based adjuvant chemotherapy after preoperative chemoradiotherapy in rectal cancer: long-term results of the EORTC 22921 randomized study. Lancet Oncol 15(2): 184-190, 2014. PMID: 24440473. DOI: 10.1016/S14702045(13)70599-0

36 Sainato A, Cernusco Luna Nunzia V, Valentini V, De Paoli A, Maurizi ER, Lupattelli M, Aristei C, Vidali C, Conti M, Galardi A, Onnticelli P, Friso ML, Iannone T, Osti FM, Manfredi B, Coppola M, Orlandini C and Cionini L: No benefit of adjuvant Fluorouracil Leucovorin chemotherapy after neoadjuvant chemoradiotherapy in locally advanced cancer of rectum (LARC): Long term results of a randomized trail (1-CNR-RT). Radiother Oncol 113(2): 223-229, 2014. PMID: 25454175. DOI: 10.1016/j.radonc.2014.10.006

37 Schrag D, Weiser M, Saltz L, Mamon H, Gollub M, Basch E, Venook A and Shi Qian: Challenges and solutions in the design and execution of the PROSPECT phase II/III neoadjuvant rectal cancer trial (NCCTG N1048/Alliance). Clin Trials 16(2): 165175, 2019. PMID: 30688523. DOI: 10.1177/1740774518824539

38 Deng Y, Chi P, Lan P, Wang L, Chen W, Cui L, Chen D, Cao J, Wei H, Peng X, Huang Z, Cai G, Zhao R, Huang Z, Xu L, Zhou H, Wei Y, Zhang H, Zheng J, Huang Y, Zho Z, Cai Y, Kang L, Huang M, Wu X, Peng J, Ren D and Wang J: Neoadjuvant modified FOLFOX6 with or without radiation versus fluorouracil plus radiation for locally advanced rectal cancer: final results of the Chinese FOWARC trial. J Clin Oncol 37(34): 3223-3233, 2019. PMID: 31557064. DOI: 10.1200/JCO. 18.02309

Received September 27, 2020 Revised October 13, 2020 Accepted October 14, 2020 